I. The number of reagents used in the digestion is reduced from four to three.

2. Frothing is obviated and the operation requires no attention except turning up the lamps until full heat is secured.

3. The time of digestion is shortened.

4. Potassium sulphide is made to do double work by acting as a reducing agent instead of sodiun thiosulphate and then being converted into potassium hydrogen sulphate serving the end secured by adding potassium sulphate in the original method.

\title{
THE SEPARATION OF ALKALOIDAL EXTRACTS.
}

BY CHARIES PLATT.

Received Octoher zo, 18 gó.

$T \mathrm{HE}$ writer has found the accompanying simple device of great value in the separation of the annoying emulsions

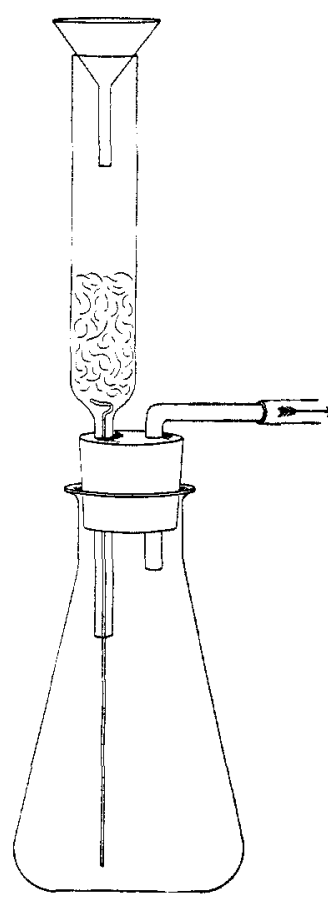
so often met with in alkaloidal anal$y$ sis, as, for instance, in the petroleum ether and benzene extractions of Dragendorff's method. The filtering tube is nineteen $\mathrm{cm}$. long, the upper $12.5 \mathrm{~cm}$. having an inside diameter of fourteen $\mathrm{mm}$., the lower contracted portion, an inside diam. eter of three mm. A stout platinum wire bent at the upper end is so placed as to pass through the constricted portion of the tube to the bottom of the eight-ounce Erlenmeyer flask. Washed cotton is firmly packed in the tube to a depth of about four $\mathrm{cm}$. and the apparatus, connected with a filter pump, is ready for use. The filtered liquids may finally be carefully poured into an ordinary separating funnel and manipulated as usual. By this method the most persistent emulsions are separated into their constituent liquids in as many minutes as ordinarily are required hours or days.

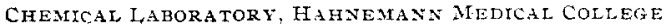

PhILADELPHIA. Pa. 